\title{
Human Psychology and the Concept of God in Indian Society
}

\author{
Stephen Edwards; Jeffrey Dufour \\ Asian Studies Graduate Diploma, Toronto, Ontario, Canada \\ https://doi.org/10.47814/ijssrr.v3i4.51
}

\begin{abstract}
The concept of God in human mind has been and will always be a diversified concept. To understand God one has to travel through his mind and its contents. The centuries of inheritance have cemented the beliefs, on which we stand today. The concept of God is different for every human but to understand the whole concept of God one has to put his inherited knowledge on bay and look what he perceives. As J. Krishnamurti says- We have to completely come out of our psychological conditioning only then there is a possibility of understanding the immense named as God. Since, primitive time till today's modern world this one word 'God' has played a major role in human living. It has travelled through the ages in human mind and to clearly understand this concept of God we have to look at our journey as mankind, without this neither we should accept nor reject the concept of God.
\end{abstract}

Keyword: God; Belief; Conditioned Belief Structure; Mind; Psyche; Subconscious; Religion

\section{Introduction}

There has always been a question in my mind about the whole concept of God that how this concept of God travelled with the human psyche which not only changed the thought process of humans but also changed the direction of entire world as we live in today. The kind of a diversification in the religious panorama and in religious aspects of human living has created a wide drift among the humans that no other aspect of life has done it. The kind of religious conflict in which we live in today's world has not only produced fear and disharmony in the world but has also completely changed the human understanding of life. If we look at the world today, this is the world of wars, destruction, suffering and agony and if we minutely analyse the root cause, we reach the religion as a basic differential factor for this anarchy. So it is important for us to understand minutely this concept of God especially in Indian context.

In prehistoric time, man first came in contact with the nature viz. the sun, moon, stars, rivers, mountains, trees, animals, etc. sometimes he was not able to understand the transformation or changes occurring in nature like day \& night, birth \& death (especially death), shadow, change of weather, natural disasters, etc. Primitive man was incapable of answering all these natural phenomena and even 
he did not have the capacity to control it or change it. All these aspects compelled the man to think that there is some power beyond the nature which controls everything around us which is considered supernatural. According to David Hume (a philosopher of $18^{\text {th }}$ century), religion is an outcome of intellectual fallacies of humans.

Anthropologists have supported the fact on the basis of artifacts found in excavation that prehistoric or early humans Neanderthals used to bury their deads with a ritual that seems to show that they anticipated life after death, in some form. They used to orient the dead bodies in a specific direction while burring them under the earth, along with all their (of dead one) tools that might be use in a future life. This proves that Neanderthals might have had based this belief on some concept of supernatural. (Kottak 2013)

It proves the believence of something beyond human capabilities which gradually developed into the different forms of beliefs like animism, naturism, animatism, fetishism, totemism, mysticism and other forms of primitive religion (as E. B. Tylor $\left(19^{\text {th }}\right.$ century evolutionist anthropologist) mentioned that the earliest form of religion was animism). During Palaeolithic times, man was the food gatherer- hunter and used to lead a nomadic life. These foragers have zoomorphic gods- animals \& plants (totemism) or worship natural phenomena such as sun, moon \& stars. Later on, when man became the food producer (during Neolithic times) and started living a community life or sedentary life, his form of worship had also changed with the change in economy. Now animism developed into mysticism. (Kottak 2013)

Gradually, in due course of time, the control over the resources of production (land, livestock, human labour and other natural resources) become very important for him. Now with the surplus production man started accumulation and hankering for holding of resources forever. This gave rise to power and authority as the group of people which hold or possess large were became the lords or rulers over the people with less resources. It was the beginning of exercise of power relations in the society and also the formation of classes with haves and haves not. As people gain more control over the environment through food production, new kinds of God appear- anthropomorphic or humanlike, ones. About whom it was believed that these deities control such natural phenomena as thunder, lightening $\&$ soil fertility. For example, in Indian context, the conception of 'Indra' as a lord of all powers of nature was considering the king of all nature deities.

It shows that as the structure of society changed from savagery to barbarism to civilization (as mentioned by L.H. Morgan- $19^{\text {th }}$ century evolutionist anthropologist, in his evolutionary scheme of development of society), a shift in the form of religion and God was also seen like from nature worship and animism to polytheism. Now more powerful gods came in existence like ruler gods or king gods and they considered as super-humans. The evidences of which can be seen in many indigenous societies of India, China, Africa, Polynesia, Mexico, Peru, and Middle East. These had powerful deities and priests, with rituals requiring worship and sacrifice. With the introduction of the ruling class, state societies have formed. In some states Kings were considered divine and rulers assumed priestly duties. He used to be the head of so many states and being portrait as one who has been chosen by the God for this position and he should be worshipped. (Kottak 2013)

Now, mystics of primitive times were transformed as a medium of communication between human and superhuman. Feudal lords started using the mystics (like shamans, diviners or priests) as to create fear and certain religious believes in the society. This was also a time when the understanding 
of supernatural power was in operation in two ways- one, for the ruling class and second, for the peasant class or the people engaged in labour activities and production. For the ruling class the concept of supernatural was a medium or an instrument to control the mass whereas for the peasants or labour class, it was a medium of protection and security and a form of saviour or liberator from all odds of life. Simultaneously, the concept of God was injected in them that the king rulers were incarnations of God, and on the contrary a different kind of human believance on supernatural as God was also developing. Their faith and belief in some supernatural power termed as God was there to help them and save them from their sufferings. When no other rescue was found of their sufferings, the shelter under the name of God became inevitable. This is so deeply enrooted in our human psyche in the form of a belief that after so many centuries still this faith in some intangible power which is omnipotent and omnipresent prevails in modern society also. On the other hand, the then ruling class or king rulers who has been projected as an incarnation of God were one of the tangible forms who had the capability to protect them from the sufferings of survival like they could feed the masses in the times of flood, famine and can protect them from enemy attacks \& wars and other odds of life.

In vedic period, to establish the position of the king ruler, the law of Karma and birth and rebirth according to these karmic effects was injected in the common masses. It was told to the common people that their birth was predecided by the God as per their karmas. This way, the division of caste classification as Brahmin, Kshatriya, Vaishya, and Shudra was established. This created a drift among the common masses and the chances of opposing the king unitedly were reduced to the minimum level. Now it was easier for the king to rule over the common masses according to the karmic pattern, secondly, king was projected as a chosen one by the God to rule and this whole new conjecture was floated by a block of the mystics those who were later converted into Rajagurus and Dharmacharyasthe persons working as middle man between God and King.

If we look at the establishment of the noble or royal or aristocratic class in different parts of the world we will find a common factor among them. This is how social stratification was established in the society. Where royal class were established as incarnation or direct descendants of God (like suryavanshi, chandravanshi, etc.) and they were born to rule and commoners were divided into caste system as per their occupational hierarchy. In due course this practice was converted into a belief and simultaneously it deeply enrooted into human psyche and become a strong habit pattern from generation to generation. It still prevails in the modern times where we have become so educated and informative but still believe in the same caste system and karmic effects.

The centuries of practice and belief of these theories or concepts of God and religion has established and changed the complete thought process of human being. The way of thinking has drastically changed. This has also made our humanity to believe the sense of insecurity in survival. In a nutshell, we can say that in prehistoric times, the basic belief on God was in the form of supernatural power. Later on, in due course of time, the kingship converted this believe into organised religion. Therefore different religions are found in the world and Hinduism is one of them. After formation of the religion deliberate moves were taken by these kings and priests to harden this religious aspect into the common mass, with the help of these personified images of God in the form of deity worshiping. When we go into the origin of Hindu religion, it does not give picture of such many deities as we see today. They have been created in due course of time out of the myths.

As from the excavation of Indus Valley Civilization (a Bronze Age civilization, 3300-1300 $\mathrm{BCE}$ ), the evidences of Shiva worship was found along with the nature worship but we don't find 
traces of Rama, Hanumana, Krishna, Ganesha and others deities at that time. Later, in the Vedic period or Vedic age (1750-500 BCE), such supernatural powers were given the name of Brahma, Vishnu \& Mahesha- the personified form of the BRAHM, working as Generator, Operator \& Destroyer. With the time more number of male and female gods, goddesses and deities were added into the Hindu religion with their different powers and domain like Durga, Shakti, Ganesha, Hanumana, etc. Like lord Ganesha emerged as a distinct deity in the 4th and 5th centuries CE, during the Gupta Period although he inherited traits from Vedic and pre-Vedic precursors. For example, in Indian perspective in Hinduism, the deity Hanumana who was a character in the epic Ramayana has been portrait differently in as many as sixteen Ramayanas written by different authors. Hanuman came to be regarded as an avatar of the god Shiva by the $8^{\text {th }}$ or 10th century CE. Even so many female deities like Kali, Durga, Saraswati, Santoshi Maa, etc. were not traceable during the time of early civilization. These all were incorporated from time to time in the journey of religion in Hindu society. The earliest known appearance of Devi or Shakti is found more than 20,000 years ago, in the Indus Valley Civilization, and thenafter during the Vedic period and further during the formative period of the Hindu epics it reached its present form during the Gupta Age (300-700 CE), and continued to expand and develop thereafter.

There has to be a purpose of incorporating these new Gods in Hindu religion and as far as I understand this purpose lies in the vested interest of the ruling class and that is hunger for power and domination. Whereas for the common mass, this gave deep psychological dependency on God as pointed out by J. Krishnamurthi - "We as a humans carry a whole lot of suffering and to undo that suffering we take shelter in the name of God, which does not end the suffering but put you one inch more in the mud of ignorance." (Krishnamurti 1954)

In regard to the concept of any God or deity like, Hanumana, Krishna, Shiva, Ganesha, Durga and others have a deep impact upon the subconscious mind of Indian society. Different structures of belief and disbelief are seen widespread all around us in our Indian society. These compel us to think and question the reason behind such beliefs and inquire as to why our society is engrossed in different spiritual or religious concepts. Is it really a social concept or the seeds of it lay somewhere deep in our human psyche from where these different systems of belief and disbelief take up their forms? To get the answer, it is necessary to enter the subconscious realm of the human mind where every human has different psychological inheritance because of his living environment \& upbringing. It is not essential to know that we have faith upon which God or Goddess, but the prime question is - why are we doing this? Why our human consciousness slavishly starts accepting and believing upon such a form about which we have no reality based evidence and simply under the influence of certain religious doctrines and scriptures.

To understand it holistically, we will have to enter our psychological sphere, not with any religious conditioning of either as a Hindu or a Muslim and so on but as a human who does not have any conditioned belief structures. In my opinion the journey of life of a human being is thoroughly a journey of thought processes or the psyche which is being lived out at a mental level and his accumulative knowledge which has been instilled in him since his childhood by his environment. For example- a corpse which is free from all kinds of mental activities does not express any concepts or beliefs and has not any dependence towards any God or Goddess. Only a living individual has the capacity to keep or leave or end up with any concept be it of religion or atheism. 
It is my postulation that the beginning of all this rests in the intense eternal craving of a human being towards his life and survival. The passion and attachment towards life and existence is the root cause of all conceptual arousal. The tireless striving of a human to save one's identity and live out one's intense craving for survival and continuity is the only basic reason which has addicted and attached the insecure human mind towards its own security. With the birth of a human being the transference of concepts starts intrinsically irrespective of their religious identity be it of a Hindu or a Muslim or so on. This is basically a part of the process of socialisation which starts just after the birth.

Our society, engrossed in insecurity and fear, transfers the knowledge of a supernatural power from one generation to the other. When we encounter our geographical, cultural and social circumstances, we find that as a human being we are completely insecure and helpless as in unforeseen circumstances like physical ailments, epidemic, natural disasters, wars, etc. man finds himself incapable and insecure. We as humans are very ill- equipped to deal with these dire straits. Further, in this visible world of reality no such state or support is evident that can save us from death. Viewing all this, humans found it appropriate to create such a state or concept which is omnipotent, omniscient and is capable of providing us with security and support under all circumstances. Thus, we created the idea of Gods and Goddesses- the personified form of supernatural powers. If you keenly observe any deity whether it is Hanumana or Krishna or Ganesha or Shiva or any other, you will find that all these established conceptualisations are said to be omnipotent, omniscient and are portrait as superhumans with all their weapons in their hands showing their power and might. This advocates that power and might are the factors which can save us from any unforeseen circumstances. Now the question arises that why the human mind clings to such insecurity and looks towards power and might as a rescue? Why are we so doubtful and fearful towards unpredictability in life?

To understand this let us look ourselves in the present world we are living in. Do we feel ourselves completely secure? Are we not fearful of unhappenings around us? The kind of society we have formed today is it healthy and secure? The insurgencies, newly emerging dangerous diseases, crime and intolerance in the society are some sufficient factors to make us insecure, isn't it? So when the mind pass through these phases of life where he is incapable of handling such situations, his fear born out of these aspects compels him to look beyond for help. Moreover, when we see around us people getting help in such situations from unknown and lot of information from a religious block being enforced then the fearful mind spontaneously clings for security which is God.

Let us explore this postulation by taking the example of Hanumana. According to the common belief, Hanumana is considered as that God who provides safety. He protects a person from danger, losses, ghosts, evil and unseen misfortunes. All these circumstances belong to either the future or the past and unpredictable nature of life. We are well aware of our limited capabilities and helplessness in dealing with unseen, unpredictable things of life. Being a human, we can handle only those situations which are known to our mind and can only search for solutions for the problems known to us, but our unpredictable existence always keep us in doubt and fear. We find no assurance of security for it. So, we created such a form for our own security and safety which has the full knowledge of this unpredictable existence and can also guarantee us complete protection against it. Perhaps this is the reason that we humans have developed a dependency on God and deities who can protect us from all misfortunes and can provide us continuity of living. Death and destruction is continually visible all around us which instils a deep fear which compels us to believe upon some omniscient, omnipresent power. 
It is not only the Hindu religion, but all the religions of the world are based upon fear. Now the question arises - is there some other reason also, behind this unflinching faith of people upon God? Fear can be the basic reason but till the point of time any individual or his mental consciousness does not tangibly pass through any experience, the belief system cannot get fixed firmly. The habit pattern of humans is a continuous chain of repeated actions and no habit ripens in one day. A perpetual repetition of any habit is necessary for it to ripen or get fixed. The human mind or consciousness is such an instrument, which always keeps on searching objects for human security. When we take up devotion towards Hanumana, then we are not just going towards a statue or a picture but we are moving into an unimaginative state or a concept with the full knowledge of that form, its different powers expressed through, famous folklores and myths. Our mind is already so pre- occupied with previous information that it keeps on searching for the repetitions of those events and the states associated with them.

There is another peculiar quality of the human mind. Mental state keeps changing (any incident or scenes as per its information) with continuous happenings in our social \& natural environment. Whenever our mind is unable to give us a clear answer about any unprecedented event or object occurring in our social life, we declare it as supernatural (unexplained or unpredicted). Since, something supernatural can be performed only by superpowers. So, we relate them with Gods and Goddesses. This is also true that a continuous chain of events keeps on taking place around us and we cannot keep a record of everything. Whenever our mind is unable to analyse any incident, we try to combine these with something supernatural. This action is repeated again and again and such repetitions had been going on since the time immemorial. This thought process creates such a kind of habit pattern in our mind that it unknowingly compels us to think only what is present in its conditioning. Now even the scientific researches approve of it stating there are uncountable mental wirings in the brain which function only on their fixed patterns and constitute the habit patterns of an individual. Like these individual habit patterns, there are also social and religious habit patterns which accept anything unthinkingly, as a group. This is one of the main reasons behind the transference of the concept of God which later on transforms into superstitions or blind faith.

Look at the world today all fanatic religious groups follow the same habit patterns repeatedly following the religious doctrines these groups have developed such a hard habit patterns those have become destructive today. Habits always disobey reasoning. You look how less logical the society has become especially in the case of religious belief. Until or unless, we human develop our power of reasoning and logic, we won't be able to counter this menace of religious fanaticism. Religious impact on human mind is so old that it has now converted into a strong habit pattern. The journey of religion which started from nature worship has now reached to the state of religious disharmony. Whole new religion sects are born. Every human has his own concept of religion which has created diversified form of religions in the world. The question is: Was the religion born to create disharmony and separation, or the religion has been highlighted by organised groups and they have changed the true essence of religion and human mind. We have to accept that no other aspect of life has this much of strong impact on human psyche than religion. Once, Karl Marx said that "Religion is the opium of the people", which suppresses the reasoning of human beings which is visible now. He said that religion has no independent history; instead it is the creature of productive forces. He believed that religion was a way for the poor to accept their poverty and for the wealthy to control the poor (Marx 1970). 
One big question is in front of us that as humans where we want to take our world? Do we want anarchy, killings, destruction in the name of religion or we want to make this world- the world of harmony, love and human association but it is sure that until or unless we go into the journey of our mind and look at our religious habits and believes we have a little hope of saving this world. According to J. Krishnamurthy- '..... from ancient history to the present day, man lived in agony, in despair, in sorrow; and he doesn't find a way out of it. Therefore he invents gods, temples, churches, all the rituals, and all that nonsense, or he escapes in different ways ......." He observes that the origin of actual religion is primarily psychological, ......" (Krishnamurthi 1956: 106). "So also with your ideals, your gods, your religions: they are the creation of the desire for escape into comfort. You yourself have made the world into a prison, a prison of suffering and conflict; and because the world is such a prison, you create an ideal god, an ideal freedom, an ideal truth." (Krishnamurthi (1933): par. 22). Similarly, Osho has said that the truth is that God himself is a creation of man's imagination. He said that naturally primitive man was not able to adjust himself to the idea of this vastness of the universe without giving it some personality and without making himself in some way related to that personality. God was an effort of the primitive mind of man to give existence a personality. Then he becomes the God, the father. Then you can make some relationship with him (Osho 1994).

It has become a necessity now for each human to know his mind and his conditioning. Until or unless we know ourself, our beliefs and disbeliefs and functioning of our mind and psyche. To understand our religion and God we should understand ourself, our journey as human, then only we can open the lock of something called God.

\section{Glossary}

- God and Diety- God and deity are synonymous. They both represent a supreme power. However, sometimes God as a term is used to represent the only supreme power, whereas deity can be used to refer to any of the forms of this supreme power and thus can be multiple in number. God is generally used in context to male gods, whereas deity can be used to refer to both god and goddess (female gods). In Hinduism, people believe that Brahma is the almighty god and other deities like Rama, Ganesha, etc., are all just other forms of the same god, Brahma.

- Belief-Belief is an acceptance that something exists or is true, especially one without proof.

- Believence - An inherent propensity to believe, independent of evidence and knowledge.

- Subconscious realm- It is one of the three stages of mind- conscious, subconscious and unconscious. Subconscious realm is like a storehouse where all our previous experiences, good or bad and acquire knowledge are stored.

- Conditioned belief structure- is a pattern in human mind which has been formed by the repetitive action and repetitive environmental conditions. When a person is born in a particular sect few conditions of that sect are being imputed in him. Repetitive belief and action solidifies that particular conditioning and spontaneously person acts on that direction without much thinking.

- Intelligence- is the ability to learn or understand or to deal with new or trying situation.

- Basic mental structure- means a crucial part of our understanding and knowledge which is used as an essential protective force like God in our daily survival.

- Brain- is a physical formation of matter which is made up of blood and flesh. It can be defined as a physical hardware that operates and coordinates with our body and environment but no 
such definition can be derived for mind which is an operating system to be understood as a software that functions in relation with our brain, physical body, environmental aspects as well as with our psyche which is a storehouse of all our experiences.

- Conscious Mind- is a state which operates while we are awake and in that state this conscious mind perceives the things from the environment.

- Psyche- in Hindi language it can be call as 'Chitta', which is a storehouse where we keep the impressions of our good and bad experiences and which becomes a guiding force of our mind.

\section{References}

Marx, Karl (1970). A Contribution to the Critique of Hegel's Philosophy of Right. London: Cambridge University Press.

Kottak, Conrad Phillip (2013). Anthropology, McGraw-Hill Education

Krishnamurthi, Jiddu (1933). Talk 4, Alpino, 6 July

Krishnamurthi, Jiddu (1954). The First and Last Freedom, San Francisco, USA: Harper \& Brothers.

Krishnamurthi, Jiddu (1956). Commentaries on Living', First Series, San Francisco, USA: Harper \& Brothers.

Krishnamurthi, Jiddu (1992). On God, San Francisco, USA: Harper One.

Osho (1994). Seeds of Wisdom. Pune: OSHO Media International.

\section{Copyrights}

Copyright for this article is retained by the author(s), with first publication rights granted to the journal.

This is an open-access article distributed under the terms and conditions of the Creative Commons Attribution license (http://creativecommons.org/licenses/by/4.0/). 